\title{
Evaluation of Functionability of Harnesses Used In the Aircraft Landing System Manufactured In the Aerospace Industry of Mexicali, B.C., Mexico
}

Research Article

Sebastian Velarde Cordova ${ }^{1}$, Francisco Ramirez Moreno', Hector Alejandro Pelaez Molina ${ }^{1}$, Homero Jaime Rodriguez Centeno ${ }^{1}$, Gustavo López Badilla $^{2}$, Elizabeth Romero Samaniego ${ }^{3}$, Sandra Luz Toledo Perea $^{3}$

${ }^{1}$ Tecnológico Nacional de México, Departamento de Ingeniería Industrial, Instituto Tecnológico de Mexicali, Mexicali, Baja California, México. ${ }^{2}$ Universidad UNEA, Departamento de Ciencias, Mexicali, Baja California, México.

${ }^{3}$ Tecnológico Nacional de México, Departamento de Ingeniería Industrial, Instituto Tecnológico de Ensenada, Ensenadai, Baja California, México.

\section{Corresponding Author}

Author Email:

glopezbadilla@yahoo.com

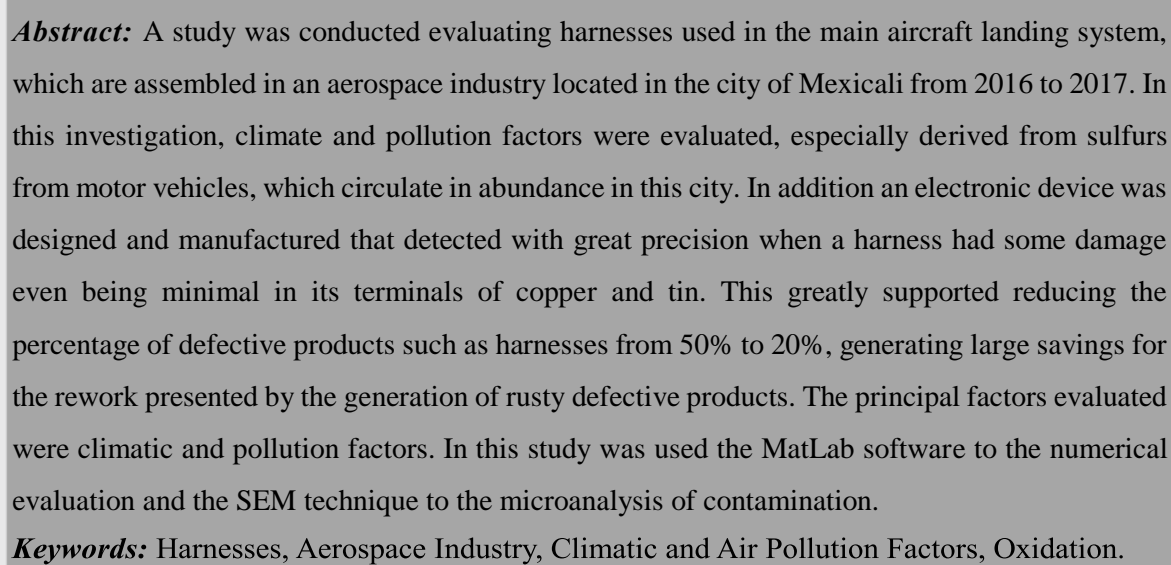

\section{INTRODUCTION}

The systems of the aircrafts have the most complex devices for the great security that need support to passengers to fly ${ }^{1}$. In the case of the study carried out, an analysis of harnesses used in the aircraft landing systems of the

Boening brand is presented ${ }^{2}$. The investigation showed small deteriorated sections with the copper wire and tin in their terminals in an oxidized way ${ }^{3}$, which sometimes generated electrical conductivity towards the landing system and sometimes did not present any kind of electrical conductivity. This in a process of simulation of the functionality of the landing system, caused by failures, which could be generate a great tragedy, to occur principally in a commercial flight of real life. This happened in the operations of a clean room, where humidity and temperature were controlled, as well as particles and polluting gases ${ }^{3,4}$, mainly with filters to detect and not allow entry to the clean room outside the company, of sulfides and oxides of nitrogen coming from vehicular traffic ${ }^{5}$. Even with specialized filters, oxidation was generated in the terminals of the harnesses. This was at certain times of the year (being in seasonal, monthly, daily and hourly periods). The harnesses were evaluated by means of an electric test machine with a plate where the terminals of the harnesses were assembled and generated an analysis of the electrical conductivity process.

\section{Aircraft landing systems}

The aviation area must take special care in all systems that make an aircraft work properly. The three main systems mentioned above are the main ones in maintaining a safe flight and avoiding tragedies as they have occurred in certain air carriers ${ }^{6,7}$. One of those that we focus on in our study is the landing system, because it contains electrical harnesses that are manufactured in a company located in the city of Mexicali. These harnesses are encased in clean rooms, which have filters that detect contaminating particles such as dust and some air pollutants, but do not have 
filters to detect gases, especially sulphides that penetrate the clean room and generate oxidation of the copper and tin terminals of the harnesses.

\section{Communication signals in the aviation}

Both the subsystems (on land) and in the aircraft are connected with electrical harnesses, which are sometimes assembled in companies other than those that completely manufacture the aircraft ${ }^{6}$. This sometimes generates some type of defective harness situation, which are originated in the manufacturing, transport or storage processes of the participating companies due to the diversity of climatic factors and air pollutants that cannot be controlled in certain regions of the world, being this case of the Mexicali city ${ }^{8}$. In this city are generated in periods mainly of winter, concentrations of air pollutants in essential sulfur from vehicular traffic, for being a city with a large number of motor vehicles. These pollutants in the form of gases penetrate the interiors of industries, especially the aerospace industry that is booming in this city in the northwest of the Mexican Republic and cause the oxidation of the copper and tin terminals of the harneses ${ }^{7}$. Sometimes the oxidations are generated and can be detected in the final test machines of harness functionality and with this, rework is generated, causing economic losses, since the rework activity is not contemplated.

\section{Deterioration of terminals of harnesses}

When the terminals were damaged, the electric test machine indicated a percentage lower than $100 \%$ and with this was considered an unreliable harness, to be assembled in the landing gear ${ }^{9}$. This caused concern to the specialized personnel and managers, because rework was elaborated that was a cost not contemplated in the planning of the production. In addition, there was concern, in executives of the Boening Company that assembled the aircraft in its entirety in a city in the state of Georgia, United States. For this reason an electronic device was proposed, being of low cost and easy to manufacture, with basic components such as transistor, resistor and electrical relay of low cost, which was detecting very quickly detect the functionality of the harnesses, in the manufacturing process of clean room of the company evaluated, as well as in the operations of unions between different harnesses ${ }^{10}$.

\section{Harnesses used in the aerospace industry}

In the aerospace industry is a lot type of harnesses that operates by the conductivity of electrical current as macro amps or microamps ${ }^{7}$. A manufacturing processes with a lot quantity of harnesses is showed in figure 1 in the Safran Company located in Chihuahua, Mexico. The harnesses are connected in the aircraft landing system with a lot

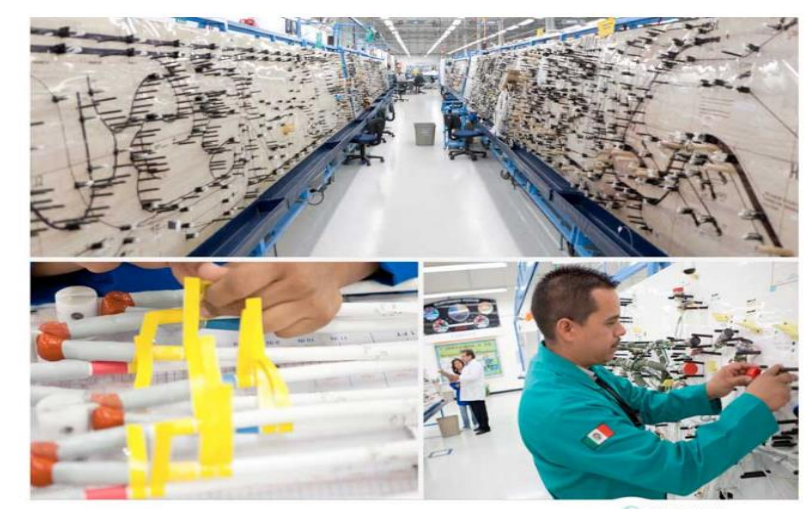

Figure 1. System of aircraft landing with Adriana Reves, $2016^{11}$ harnsesses electrical connections and debit be in terminals of copper and $\operatorname{tin}^{12}$.

\section{Electrical conductivity in harnesses}

The operation of the harnesses is by electrical conductors that are constituted principally of metals of aluminium, copper, gold, silver, nickel and tin. One of metal most used if the copper for its cost and excellent electrical properties and also it is a manageable material ${ }^{8}$. The 
majorly of the harnesses is fabricated of this material, but is very susceptible to the air pollution principally of sulfurs. The electrical conductivity in the harnesses can be as a macroamps and microamps essentially, and some industrial machines of electrical probe in some times can`t detect any failure in harnesses essentially in functions with micro amps.

\section{Basic electronic devices}

A lot quantity of electronic devices is used in the aerospace industry, for its functionability, that forms the electrical circuits and with this the electrical harnesses used in the aircraft systems ${ }^{1}$. The principal basic electronic devices (BED), which are called electrical semiconductors, are the resistor, inductor, capacitor and transistor that form great variety of integrated circuits (IC) that are known as electronic chips. Respect to this investigation, the BED were used to design and fabricate the electronic device used to detect very fast and easy the particles of air pollutants as dust as physical contamination and chemical agents as sulfurs ${ }^{11}$.

\section{Numerical analysis}

The evaluation was made with the MatLab software ${ }^{13}$ with statistical methods as the correlation analysis to compare with a detail the causes and effects of the defective harnesses.

\section{METHODOLOGY}

This study was made to evaluate the climatic and pollution as dust and sulfurs as the principal factors with specialized filters. When the atmospheric evaluation was finished, an electronic device was designed and fabricated to detect with a lot security, the agents that generates a bad operation of the electrical and electronic devices. The physical and chemical agents were added to the electrical connections of the electrical connections of the electronic device used as evaluator system that simulated the operation an electrical harness of the aircraft systems. In this investigation were used the ASTM ${ }^{14,15}$ and Standards ISO $^{16,17,18}$ to evaluate the effect of the presence of air pollutants being physical and chemical agents. The evaluator electronic device is represented in figure 2 .

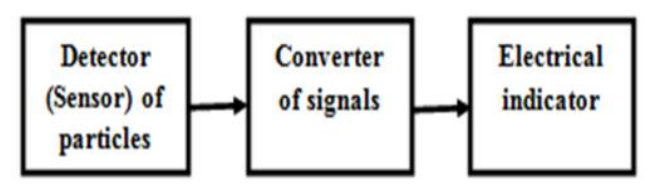

Figure 2. Steps of the evaluator electronic device

The evaluator electronic device (EED) was represented of three steps explained next. The first step indicates a detector of metallic surface as electrical connector to identify the presence of physical and chemical agents added to the electrical connector of the EED. The second step shows the converter of signals, indicating the presence of air pollutants mentioned above in the electrical connections as an electrochemical signal and converted to electrical signal of the EED. The third step was represented the electrical indicator with a focus of 25 watts, indicating when the EED was functions good and bad and shows the same operation of the harnesses. The mathematical evaluation was with the MatLab software and the microanalysis was made with the SEM technique of a private company. 
RESULTS

\section{Evaluation of productivity}

This represents the same operation of the harnesses and this function in the aircraft system. Figure 3 and 4 shows the relation of productivity, defective products and atmospheric factors.

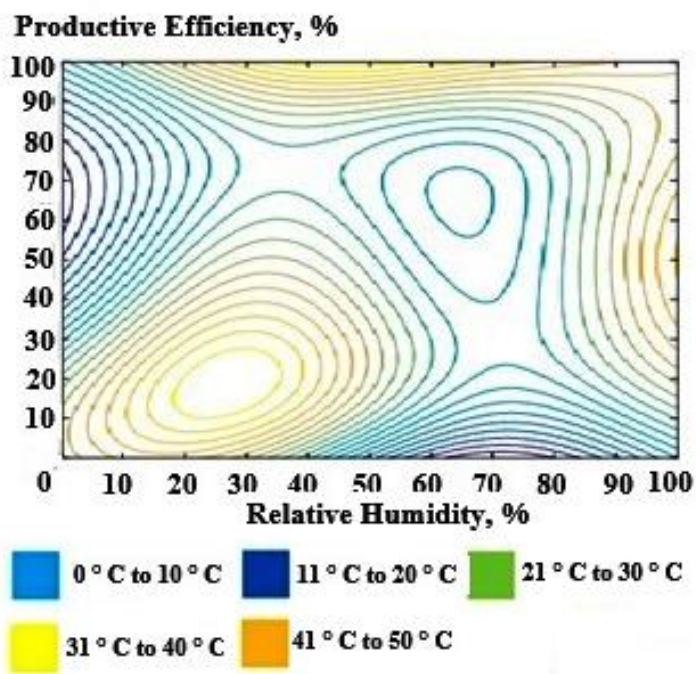

Figure 3. Correlation analyses of climatic factors with productive efficiency.

Figure 3 shows the correlation analysis of climatic factors and productivity efficiency, where the analysis indicates the effect of these factors in the percentage of the productivity. The evaluation in the clean room of industry analyzed, shows the color of lines, involving the ranges of temperature, because was the parameter that have more effect in the productivity efficiency, and with changes of temperature, are a great relation with the relative humidity. The productivity efficiency indicated three ranges: $0 \%$ to $40 \%$ (means finish $50 \%$ of goals of production percentage), $41 \%$ to $70 \%$ (means finish $75 \%$ of goals of production percentage) and 71 to $100 \%$ (means finish $100 \%$ of goals of production percentage).

Figure 3 indicates that with relativity humidity from $0 \%$ to $50 \%$ and temperature from $30{ }^{\circ} \mathrm{C}$ to $45{ }^{\circ} \mathrm{C}$, was presented low productivity efficiency from $0 \%$ to $40 \%$. At relativity humidity from $0 \%$ to $30 \%$ and temperature from $0{ }^{\circ} \mathrm{C}$ to $20{ }^{\circ} \mathrm{C}$, the productivity efficiency was from $40 \%$ to $90 \%$. With relativity humidity from $40 \%$ to $100 \%$ and temperature from $0{ }^{\circ} \mathrm{C}$ to $20{ }^{\circ} \mathrm{C}$, the productivity efficiency was from $0 \%$ to $25 \%$. At relativity humidity from $50 \%$ to $85 \%$ and high temperature from $0{ }^{\circ} \mathrm{C}$ to $20^{\circ} \mathrm{C}$, the productivity efficiency was high (20\% to $80 \%$. With relativity humidity from $25 \%$ to $75 \%$ and temperature from $30{ }^{\circ} \mathrm{C}$ to $40{ }^{\circ} \mathrm{C}$, the productive efficiency was from $90 \%$ to $100 \%$.

\section{SEM analysis}

To determine the grade of deterioration of the metallic connections of copper of harnesses, was utilized the microanalysis with the SEM technique. This was by a private company with cooperate with the analysis with the educational institution of authors. Figure 4 shows the negative effect of the air pollution of dust and sulfures particles as gas that penetrate to the clean room of the industry evaluated. 


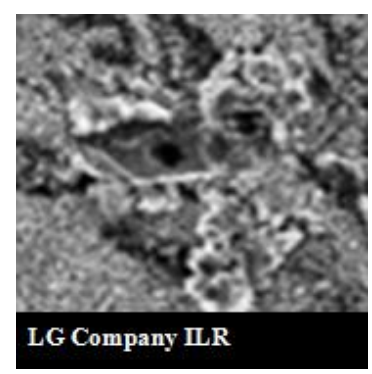

Figure 4. Microanalysis of deterioration of electrical connections of harnesses

The white points represented in figure is dust added, where the temperature and relative humidity were important factors to generate the addition of particles. The black points were particles of sulfurs added with the same process with the temperature and relative humidity, as the principal climatic factors, of the deterioration of the metallic surfaces.

\section{CONCLUSIONS}

The presence of air pollutants as dust as particles and sulfurs as particles and gases, deteriorate the metallic connections of harnesses and this causes a defective product. This is because can't can used to the aircraft landing system that can originates a great tragedy if this causes a failure in fly. This occurred in a clean room of a company located in the Mexicali city, with restricted standards. This cause economic losses and concerned to owners, managers and specialized people. For this reason was made the investigation with people of the company evaluated with the specialized in industrial, electronics and environmental topics of the Tecnologio Nacional de Mexico, with two campus located in the Instituto Tecnologico de Mexicali and the Instituto Tecnologico de Ensenada. Researchers for both educational institutions, designed, fabricated and tested the electronic device to detect the unfuncionability of the electrical harnesses very easy and fast.

\section{REFERENCES}

1. B.G. Lopez, S.B. Valdez, K. R. Zlatev, P.J, Flores, B.M. Carrillo and W. M. Schorr (2007). Corrosion of metals at indoor conditions in the electronics manufacturing industry; Anti-Corrosion Methods and Materials; Vol. 54 (6) pp. 354-359; https://doi.org/10.1108/00035590710833510.

2. Chongchen Xu (2003); Corrosion in Microelectronics; Partial Fulfillment of MatE pp. 234.

3. L. Veleva, B. Valdez, G. Lopez, L. Vargas and J. Flores (2008); Atmospheric corrosion of electro-electronics metals in urban desert simulated indoor environment; Corrosion Engineering Science and Technology; Vol. 43 (2); pp. 149-155; https://doi.org/10.1179/174327808X286275.

4. Moncmanova A. (2007); Environmental Deterioration of Materials, WIT Press, pp 108-112.

5. Cerrud-Sánchez. S.M, Armendáriz J., Ortiz-Prado V.H., Schouwenaars R.(2005); Deterioro por corrosión atmosférica de componentes electrónicos de equipo telefónico; INGENIERIA. Investigación y Tecnología; Vol. VI, Núm. 4, Octubre-Diciembre, 2005, pp. 219-238; ISSN: 1405-7743.

6. The National Historic Landmarks Program, U.S. Department of the Interior Washington, D.C. and United States Air Force Wright-Patterson Air Force Base Ohio. (2011). American Aviation Heritage; pp. 320; retrieved from http://citeseerx.ist.psu.edu/viewdoc/download;jsessionid=76FF7BD9A0C9CFE932698E4A8E68DC46?doi=10.1.1.369.9190 $\&$ rep=rep1\&type $=$ pdf 
7. UPDATE (7 Sept): Installation of the second new Instrument Landing System (ILS) began on Sunday 6 September. This is being installed at the Western end of the Southern Runway; (2015, August 20th); retrieved from https://your.heathrow.com/first-of-4-new-landing-systems-installed-at-heathrow/.

8. López Badilla, Gustavo; Arreola Álvarez, Rosa Angélica; Martínez Valdez, Lluvia S.; Mendieta Rodríguez, Yuliana; García Rodríguez, Mariela; Pérez Marmolejo, María del Carmen; Rocha Crespo, José L. (2012). Corrosion of electronic devices of the electronics industry of Mexicali, B.C. México influenced by H2S pollution; Nova Scientia, Vol. 5 (9); pp. 29-41; E-ISSN: 2007-0705.

9. Gustavo López Badilla, Hugo Tiznado Vázquez, Gerardo Soto Herrera, Wencel De la Cruz Hernández, Benjamín Valdez Salas, Miguel Schorr Wiener y Roumen Zlatev. (2010). Corrosión de dispositivos electrónicos por contaminantes atmosféricos en interiores de plantas industriales de ambientes áridos y marinos; Nova Scientia, No 5 Vol. 3 (1); pp. 11-28.

10. Lopez Badilla Gustavo, Valdez Salas Benjamin, Schorr Wiener Miguel, Rosas Gonzalez Navor, Tiznado Vazquez Hugo, Soto Herrara Gerardo, (2010) "Influence of climate factors on copper corrosion in electronic equipment and devices", Anti-Corrosion Methods and Materials, Vol. 57 Issue: 3, pp.148-152, https://doi.org/10.1108/00035591011040119.

11.Reyes Adriana. (2016-02-12). Safran harnesses en su nueva planta; retrieved from https://diario.mx/Economia/2016-02-12_7dc81ddb/safran-hara-arneses-en-su-nueva-planta/

12. Gustavo Lopez, Hugo Tiznado, Gerardo Soto Herrera, Wencel De la Cruz, Benjamin Valdez, Miguel Schorr, Zlatev

Roumen, (2011) "Use of AES in corrosion of copper connectors of electronic devices and equipments in arid and marine environments", Anti-Corrosion Methods and Materials, Vol. 58 Issue: 6, pp.331-336,

https://doi.org/10.1108/00035591111178909

13. Magrab Edward B., Azarm Shapour, Balachandran Balakumar, Duncan James H., Herold Keith E., Walsh Gregory C. (2011). An Engineer's Guide to MATLAB ${ }^{\circledR}$ With Applications from Mechanical, Aerospace, Electrical, Civil, and Biological Systems Engineering Third Edition; Copyright @ 2011, 2005, 2000 Pearson Education, Inc., publishing as Prentice Hall, One Lake Street, Upper Saddle River, New Jersey 07458. retrieved from http://phylab.fudan.edu.cn/lib/exe/fetch.php?media=home:xiaole:an_engineer_s_guide_to_matlab_.pdf

14. ASTM G84 - 89(2005) Standard Practice for Measurement of Time-of-Wetness on Surfaces Exposed to Wetting Conditions as in Atmospheric Corrosion Testing ASTM G84 - 89 (2005).

15. ASTM G91 - 97(2004) Standard Practice for Monitoring Atmospheric SO2 Using the Sulfation Plate Technique.

16. ISO 9223, Corrosion of Metals and Alloys. Corrosivity of Atmospheres, Classification, International Organization for Standardization, Geneve, Switzerland, 1992.

17. ISO 11844-1:2006. Corrosion of metals and alloys - Classification of low corrosivity of indoor atmospheresDetermination and estimation of indoor corrosivity. ISO, Geneva, 2006.

18. ISO 11844-2:2005. Corrosion of metals and alloys - Classification of low corrosivity of indoor atmospheres Determination and estimation attack in indoor atmospheres. ISO, Geneva, 2005. 